\title{
ADOÇÃO NO SISTEMA JURÍDICO BRASILEIRO
}

\author{
Amanda Marques Abraham, Mayara Vallim \\ Universidade do Oeste Paulista - UNOESTE, curso de Direito, Presidente Prudente, SP. E-mail: \\ nana_abraham@hotmail.com
}

\section{RESUMO}

Essa pesquisa tem como objetivo geral realizar um estudo sobre a Adoção no sistema jurídico Brasileiro nos dias atuais, fazendo um breve apanhado sobre a sua evolução histórica e abrangendo assim os principais pontos desse instituto que se faz presente no ordenamento jurídico, compreender os requisitos necessários a serem preenchidos para que se concretize de fato e de direito a adoção, bem como analisar sobre o que dispõe a Lei. 8.069/1990 Estatuto da Criança e do Adolescente com relação à adoção, observando a grande evolução do instituto, que nos dias de hoje coloca em primeiro lugar a proteção e bem estar da criança e adolescente.

Palavras - chave: Adoção; Leis; Proteção; Crianças; Brasil

\section{ADOPTION IN THE BRAZILIAN LEGAL SYSTEM}

\begin{abstract}
This research has as general objective to carry out a study on the Adoption in the Brazilian legal system in the present day, making a brief survey of its about its historical evolution and covering the main points of this institute that is present in the legal system, understanding the necessary requirements to be fulfilled in order to materialize in fact and the right to adoption, As well as to analyze about the provisions of the Law. 8.069 / 1990 Child and Adolescent Statute with regard to adoption, observing the great evolution of the institute, which today places first the protection and well-being of the child and adolescent.
\end{abstract}

Keywords: Adoption; Laws; Protection; Children; Brazil

\section{INTRODUÇÃO}

Apesar de o mundo e a história ter evoluído em vários aspectos ao longo dos anos, ainda hoje encontramos situações de desigualdade, uma delas esta relacionada ao abandono ou maus tratos de crianças que é o motivo precursor para levá-los aos abrigos. Adotar uma criança em tempos atrás era algo constrangedor a um casal, pois mostrava a incapacidade que existia entre eles de gerar uma. Hoje com a evolução da sociedade, adotar uma criança é compreendido como um ato de amor, solidariedade e necessidade, logo que o índice de crianças e adolescentes abandonados por uma infinidade de motivos no Brasil só aumenta.

O ideal, e o que é estabelecido na Lei 8.069/90 ECA, é que a criança permaneça no seio de sua família, sendo retirada dela somente quando não houver mais condições de nela permanecer.

Porém existe hoje um índice muito elevado de crianças e adolescentes em abrigos espalhados pelo Brasil aguardando uma família disposta-a adotá-las, mas da mesma forma que existe uma infinidade de crianças, também existe uma infinidade de famílias a procura de uma criança, o que impede o caminhar dessa fila muitas vezes é a perspectiva ou o interesse das famílias cadastradas no CNA (Cadastro Nacional de Adoção). 
A maioria das famílias se cadastram com interesse em adotar um bebe ou uma criança de meses, de cor branca, entre outras exigências, e por esse motivo crianças "maiores" vão ficando para trás, muitas famílias não querem crianças com idade maior por acreditar ser mais difícil a interação, a educação e vários outros fatores, adotar um bebe é muito mas cômodo, mas o principal motivo pelo qual o índice de menores em abrigos só aumenta esta especialmente relacionado a idade.

O ECA conferiu a criança o direito de ser respeitada, amada, cuidada e todos os outros direitos conferidos aos filhos consanguíneos da família que a adote. Portanto, esse trabalho tem como objetivo mostrar a evolução do instituto da adoção no Brasil, bem como o procedimento a ser tomado por aqueles que pretendem adotar alguma criança.

\section{METODOLOGIA}

Trata-se de um estudo voltado ao Direito de Família, na área de Direito Civil que integra a adoção no universo jurídico. Consiste em uma análise de leis, bibliografias e doutrinas, para se mostrar a importância da evolução do sistema brasileiro, que acolhe cada vez mais as crianças e adolescentes.

\section{RESULTADOS}

A sociedade passou por uma longa fase de transformação até chegarmos onde estamos hoje, com mais tolerância, menos preconceito, mais respeito pelo próximo. $\mathrm{O}$ fato de adotar uma criança com disposição para amar, respeitar, educar e proporcionar um lar estável é muito gratificante, independente da questão sanguínea. É preciso investir nas crianças educá-las e mostrar o caminho do bem, pois a criança de hoje será o adulto de amanhã. As leis criadas pensando em proteger as crianças só contribuirá para que elas vivam outra realidade e se tornem cidadãos honestos.

\section{DISCUSSÃO}

Antigamente pouco se falava em adoção, havia várias possibilidades de adoção de acordo com a cultura de cada época sem uma regulamentação efetiva e sem garantias ao adotado, nesse tempo a finalidade do casamento era o nascimento dos filhos e a adoção beneficiava os casais que não podiam tê-los.

O Código Civil Brasileiro de 1916, não falava sobre o instituto da adoção, a regulamentação do assunto veio junto com a Constituição Federal em 1988, onde passou a tratar de forma diferenciada a adoção, dando ao adotado os mesmos direitos atribuídos ao filho consanguíneo. Junto com a Constituição Federal veio a Lei $n=8.069 / 90$ Estatuto da Criança e do Adolescente que atualmente regulamenta a adoção. A sistematização do instituto veio com o Código Civil de 2002, passando a disciplinar de maneira ordenada a adoção, com uma visão voltada a dar aqueles a quem a natureza não concedeu a possibilidade de ter um filho.

Posteriormente surgiu a Lei no 12.010/09 que dispõe sobre adoção, revogando o que trazia o Código Civil, e alterou vários dispositivos do Estatuto da Criança e do Adolescente. Hoje o instituto da adoção é regulado especialmente pelo ECA.

Toda essa evolução tem como objetivo proporcionar as crianças sejam elas órfãos ou abandonadas, melhores condições de vida, buscando sempre a dignidade conferida ao ser humano.

Hoje a adoção é encarada de forma mais responsável e comprometida. Adotar uma criança é torná-la filho sem nenhuma distinção do filho de sangue, amar, educar, proporcionar dignidade, 
e contribuir para que aquela criança que por qualquer motivo foi excluída, seja reinserida na sociedade e se torne um cidadão de bem.

Nada mais representa esta figura que o ato civil pelo qual alguém aceita um estranho na qualidade de filho. Corresponde à aquisição de um filho através de ato judicial de nomeação. ( RIZZARDO, 2014)

Para melhor entendimento, na concepção de Nehemias Domingos de Melo (2014, p. 136) a adoção:

É o ato jurídico solene e personalíssimo, de natureza complexa por depender de decisão judicial, através do qual alguém estranho é introduzido na família do adotante como filho, desde que observados os requisitos legais.

É importante salientar que o ECA - Estatuto da Criança e do Adolescente, em seu art. 10 , 2ㅇ assegura a criança e ao adolescente o direito de permanência no seio de sua família consanguínea. A adoção é ultima situação, e só será deferida quando não existir mais a possibilidade de que a criança fique com a família natural ou extensa, essa definição de famílias é trazida pelo ECA, em seu art. 25.

Art. 25. Entende-se por família natural a comunidade formada pelos pais ou qualquer deles e seus descendentes.

Parágrafo único. Entende-se por família extensa ou ampliada aquela que se estende para além da unidade pais e filhos ou da unidade do casal, formada por parentes próximos com os quais a criança ou adolescente convive e mantém vínculos de afinidade e afetividade.

Entende Roberto Senise Lisboa (2013, pg. 311) que:

A inserção de uma criança ou de um adolescente em família substituta constitui medida de caráter excepcional, adotada após se tentar manter o menor na família natural ou ampliada, vindo a ser implementada sempre no bem-estar do adotando.

Após um breve apanhado sobre a evolução histórica do instituto da adoção passaremos a analisar como de fato é o trâmite do mesmo, de acordo com a Lei Brasileira nos dias atuais. Hoje o principal objetivo da doação como já dito é a proteção para com as crianças e adolescentes que vivem em situações de risco ou até mesmo o abandono, ao contrário do que era reconhecido a alguns anos atrás.

De um modo geral a adoção pode ser feita por qualquer pessoa desde que preenchidos os requisitos dispostos no ECA, sendo elas casadas, solteiras, divorciadas, ou seja, não importa o sexo, estado civil e a nacionalidade, importante é que essa pessoa seja maior de 18 anos, seja capaz e tenha estabilidade para poder dar todo o suporte necessário ao adotado, a exceção a essa regra direcionada ao estado civil do adotante é quando se tratar de adoção cumulativa a qual é feita por duas pessoas simultaneamente, nesta a Lei só admite se ambos forem casados ou que vivam em união estável.

Uma observação que deve ser feita é com relação a diferença de idade do adotante para com o adotado, o Estatuto da Criança e Adolescente em seu artigo 42, § 3 o diz que o adotante deverá ser pelo menos dezesseis anos mais velho que o adotando. 
"Exigindo-a, quer a lei no lar instituir ambiente de respeito e austeridade, resultante da natural ascendência de pessoa de mais idade sobre outra mais jovem, como acontece na família natural, entre pais e filhos". (MONTEIRO, 2012, p. 477).

Essa mesma regra se aplica nos casos de adoção de maiores de 18 anos, esta é regulada pelo Código Civil em seu artigo 1.619, podendo ser aplicada no que couber as regras do Estatuto da Criança e do Adolescente.

Nesse diapasão, Arnaldo Rizzardo (2014, p. 470) estabelece que:

$\mathrm{Na}$ verdade, deve existir entre o adotante e o adotado uma idade não muito distanciada. Do contrário, nem sempre o adotante tem uma disposição e um preparo, próprios para a criação e educação de uma criança. Nem se adaptaria a uma situação totalmente diferente, com abertura para novas idéias e atitudes.

A adoção é considerada um ato íntimo, por isso é dispensável o consentimento do cônjuge para tal ato, devendo tê-lo somente se o ato for constar no nome do casal, neste caso deve haver a concordância do companheiro (a).

"Em duas hipóteses é dispensado o consentimento: se desconhecidos os pais ou se destituídos do poder familiar." (RIZZARDO, 2014, p. 472). O Estatuto da Criança e do Adolescente fala também em consentimento que advêm dos pais biológicos ou dos representantes legais do adotando se o mesmo for menor e incapaz, sendo dispensado nas hipóteses trazidas acima.

Cabe concordância ao maior de doze anos, considera-se importante a manifestação expressa do adotando, assim deverá se apurar a presença de desejo, o que se faz necessário para possibilitar a convivência. Mesmo existindo a falta de amadurecimento do adotando, já tem noção do que lhe faz bem e sabe externar os sentimentos pessoais e preferências. Demonstrando a criança sinais de que aceita ou não a adoção, o juiz apreciara corretamente os elementos e decidirá o desfecho da adoção.

O Estatuto da Criança e do Adolescente estabelece um rito processual a ser seguido pela família disposta a adoção.

De inicio, a família deve procurar um advogado, que elaborará uma petição que será encaminhada ao Cartório da Vara da Infância e Juventude, depois de aprovada o nome da família passara a constar no cadastro nacional de habilitados a adoção, CNA (Conselho Nacional de Adoção), a respeito deste assunto enfatiza GONÇALVES (2017, p. 380):

A referida Lei Nacional da Adoção estabelece prazos para dar mais rapidez aos processos de adoção, cria um cadastro nacional para facilitar o encontro de crianças e adolescentes em condições de serem adotados por pessoas habilitadas e limita em dois anos, prorrogáveis em caso de necessidade, a permanência de criança e jovem em abrigo.

Posteriormente a esse procedimento os pretendentes deverão participar de um curso de preparação psicossocial e jurídica para adoção, de caráter obrigatório.

Os pretendentes poderão escolher o perfil da criança, podendo optar por determinado sexo, faixa etária, estado de saúde, entre outras características. É importante ressaltar que a lei 8.069/90 prevê em seu art. $28 \S 4$ 으, que quando a criança possuir irmãos, o grupo familiar não seja desfeito para que não se rompa o vinculo de família consanguínea.

A partir do laudo da equipe técnica da Vara e do parecer emitido pelo Ministério Publico, o juiz proferirá sua sentença. Com o pedido acolhido o nome dos pretendentes será inserido nos 
cadastros validos por dois anos em território nacional. Aprovada a família se inclui automaticamente na fila de adoção do seu estado e permanecerá aguardando até aparecer uma criança compatível com o perfil fixado na entrevista técnica.

Deve ser destacado que a inscrição no registro civil é elemento complementar para a adoção, sendo que se refere a abertura de um novo registro de nascimento, pois será cancelado o original, atribuindo ao adotado o nome da família adotante após a sentença judicial. (RODRIGUES, 2004).

Outro ponto importante a respeito da adoção, é em relação a adoção por casais homoafetivos, apesar de ser um tema ainda polemico, ele vem aos poucos sendo aceito pela sociedade, logo que a legislação brasileira não faz nenhuma menção a orientação sexual do adotando, os casais homossexuais tem direito a constituir uma família sem empecilhos, adotar uma criança dar a ela amor, educação e um lar estável.

Perlustra Aimbere Francisco Torres sobre o assunto:

Destarte, partindo do pressuposto de que o tratamento a ser dado às uniões entre pessoas do mesmo sexo, que convivem de modo durável, sendo essa convivência pública, contínua e com o objetivo de constituir família, deve ser o mesmo que é atribuído em nosso ordenamento às uniões estáveis, resta concluir que é possível reconhecer a essas pessoas o direito de adotar em conjunto. (TORRES, 2009, p. 115)

A Constituição Federal em seu art. 226 fala da família como base da sociedade, mas não diz em nenhum momento que a composição correta da família é a união do homem e da mulher, bem como também não é dito em nenhum outro diploma do nosso ordenamento jurídico.

Da mesma maneira também a jurisprudência brasileira vem entendendo que a união homossexual é entidade familiar, possuindo características de união estável.

Logo a adoção por homossexuais não se diferencia da adoção por heterossexuais, antes de tudo o que deve ser questionado é a capacidade de cuidar da criança que a família seja ela homoafetiva ou não, dispõe.

O processo de adoção para homossexuais ocorre da mesma maneira que ocorre para os heterossexuais, o único impedimento encontrado por eles é o preconceito da sociedade.

\section{CONSIDERAÇÕES FINAIS}

Com base no estudo desenvolvido neste trabalho, é possível afirmar que apesar de toda essa segurança jurídica que a legislação brasileira proporciona a criança, o Brasil ainda encontra dificuldades. $\mathrm{O}$ ato de adotar é lindo, mas talvez seja preciso que nossos governantes revejam a situação em que se encontra o nosso País.

Oferecer dignidade ao homem, ou seja, acesso a educação, a saúde, saneamento básico e principalmente emprego, para que ele tenha melhores condições morais e materiais, e não sinta necessidade de abandonar sua família, logo que a família é a base de tudo como assegura a nossa Constituição Federal. Infelizmente o maior índice de menores abandonados vem das famílias menos favorecidas menos instruídas, o que torna evidente o quão desestruturada é boa parte das famílias brasileiras.

\section{REFERÊNCIAS:}


BRASIL. Constituição (1988). Constituição da Republica Federativa do Brasil. Brasília: Senado Federal, 1988.

BRASIL. Código Civil. Coordenação de Mauricio Antônio Ribeiro Lopes. 5. Ed. São Paulo: Revista dos Tribunais, 2000.

BRASIL. Congresso Nacional. Lei $n^{\circ}$. 8.069, DE 13 DE JULHO DE 1990. Dispõe sobre o Estatuto da Criança e do Adolescente e dá outras providências. Diário Oficial da União, Brasília, DF, 13 de julho de 1990. Disponível em:

< http://www.planalto.gov.br/ccivil_03/leis/L8069.htm>. Acesso em: 15 ago. 2017.

GONÇALVES, Carlos Roberto. Direito civil brasileiro, v. 6 - Direito de família, 14a edição., 14th edição. Editora Saraiva, 2017.

Lisboa, Roberto Senise. Manual de direito civil, v. 5: direito de família e sucessões / Roberto Senise Lisboa. - 8. ed. - São Paulo : Saraiva, 2013.

Melo, Nehemias domingos de. Lições de Direito Civil: Família e Sucessões (v.5). Atlas, 04/2014.

MONTEIRO, Washington Barros, SILVA, Reina Beatriz da. Curso de Direito Civil - Vol. 2 - Direito da Família, 42a edição. Saraiva, 03/2012.

RIZZARDO, Arnaldo. Direito de família, 9ạ edição. Forense, 2014. Disponível em: <https://integrada.minhabiblioteca.com.br/\#/books/978-85-309-5837-4/cfi/6/58!/4/2/2@0:0> Acesso em 15 ago. 2017.

RODRIGUES, Silvio. Direito Civil - Direito de família - Volume 6 - 28a Edição - Coleção Direito Civil. Saraiva, 07/2004.

TORRES, Aimbere Francisco. Adoção nas relações homoparentais. 1. ed. São Paulo: Atlas, 2009. 